\title{
ANALISIS KELAYAKAN TEKNIS UKURAN DERMAGA DAN KOLAM PELABUHAN DI PELABUHAN PERIKANAN SAMUDERA NIZAM ZACHMAN JAKARTA
}

\author{
Muhammad Suni Ramli, Dwi Ernaningsih \\ Fakultas Perikanan dan Ilmu Kelautan \\ Universitas Satya Negara Indonesia
}

\begin{abstract}
ABSTRAK
Penelitian bertujuan untuk (1) menganalisis ukuran dermaga saat ini berdasarkan jumlah dan dimensi kapal yang melakukan tambat di dermaga. (2) Menganalisis luas kolam saat ini berdasarkan jumlah kapal yang memanfaatkan kolam pelabuhan. (3) Menghitung rasio pemakaian dermaga di pelabuhan berdasarkan jumlah jam pemakaian, panjang kapal, panjang dermaga dan jumlah hari pemakaian dermaga. (4) merencanakan penataan kapal di pelabuhan perikanan. Penelitian ini dilaksanakan pada bulan Juli s/d Agustus 2018, bertempat di PPS Nizam Zachman Jakarta

Hasil penelitian menyatakan bahwa panjang dermaga yang tersedia saat ini dapat melayani tambat dengan ukuran kapal yang berbeda. Cara tambat horisontal sebanyak 88 unit kapal dan jumlah kapal yang dapat merapat tambat dengan vertikal di dermaga sebanyak 251 unit kapal. Luas kolam pelabuhan yang tersedia $40 \mathrm{Ha}$ jumlah kapal maksimum yang berlabuh sebanyak 494 kapal, saat ini jumlah kapal yang berada di kolam pelabuhan sebanyak 756 kapal maka luas kolam pelabuhan saat ini tidak dapat melayani kapal yang tambat namun kedalaman dan alur pelayaran yang tersedia saat ini masih dapat melayani kegiatan kapal di kolam pelabuhan. Kapal perikanan yang melakukan tambat dipelabuhan saat ini lebih dari 3 hari, hasil perhitungan rasio penggunaan dermaga menunjukkan bahwa waktu yang maksimal dapat diterima agar tidak perlu dilakukan penambahan dermaga adalah 6 hari, apabila waktu tambat lebih dari waktu maksimal tersebut maka perlu dilakukan penambahan dermaga.
\end{abstract}


Kesimpulan dari penelitian ini adalah penataan dermaga belum optimal, dikarenakan masih tercampurnya berbagai aktifitas kegiatan di dermaga. Oleh sebab itu perlu dilakukan penataan dermaga berdasarkan aktivitas kapal. Zonasi pemanfaatan dermaga oleh kapal perikanan di PPS Nizam Zachman Jakarta sebaiknya dilakukan berdasarkan jenis aktivitas kapal dan ketersedian fasilitas pelabuhan

\section{Kata Kunci: IMC (Index Of Market Connection), Keterpaduan Pasar, Jangka Pendek, Jangka Panjang.}

\section{PENDAHULUAN}

Pelabuhan Perikanan Samudera (PPS) Nizam Zachman Jakarta merupakan pelabuhan perikanan di Provinsi DKI Jakarta. Tingkat aktivitas pemanfaatan dermaga dan kolam pelabuhan di PPS Nizam Zachman Jakarta sangat tinggi. Saat ini zona pembongkaran ikan, tambat, perbekalan, dan aktivitas kapal non perikanan di kolam pelabuhan belum ditentukan. Oleh sebab itu perlu dilakukan penelitian mengenai analisis kelayakan teknis ukuran dermaga dan kolam pelabuhan di PPS NizamZachman Jakarta.

Penelitian bertujuan untuk (1) menganalisis ukuran dermaga saat ini berdasarkan jumlah dan dimensi kapal yang melakukan tambat di dermaga. (2) Menganalisis luas kolam saat ini berdasarkan jumlah kapal yang memanfaatkan kolam pelabuhan. (3) Menghitung rasio pemakaian dermaga di pelabuhan berdasarkan jumlah jam pemakaian, panjang kapal, panjang dermaga dan jumlah hari pemakaian dermaga.

(4) merencanakan penataan kapal di pelabuhan perikanan.

\section{METODOLOGI}

Penelitian ini dilaksanakan pada bulan Juli s/d Agustus 2018, bertempat di PPS Nizam Zachman Jakarta. 
Penelitian ini menggunakan metode studi kasus yang terjadi di PPS Nizam Zachman Jakarta terkait dengan operasional kapal di dermaga dan mencermati peristiwa/kejadian yang terjadi.

Analisis data :

- Analisis kebutuhan dermaga

Panjang dermaga yang digunakan untuk merapat beberapa kapal didasarkan pada panjang kapal rerata. IMO (International Maritim Organization) memberikan persamaan untuk menentukan panjang dermaga, (Triatmodjo, 2010) :

$L=n L o a+(n+1) x 10 \% x$ Loa ...Persamaan (1)

Keterangan :

L : Panjang dermaga

$\mathrm{N} \quad$ : Jumlah kapal yang ditambat

Loa : panjang kapal yang ditambat

cara tambat kapal tegak lurus

$L=n(B+0.5 B)$ Persamaan (2)

\section{Keterangan :}

L : : Panjang dermaga

$\mathrm{N} \quad$ : Jumlah kapal yang ditambat

B : Lebar kapal yang ditambat

0,5 Ruang kebebasan

10. Analisis kebutuhan kolam pelabuhan 
Analisis luas kolam pelabuhan saat ini dengan cara menghitung luas kolam dengan digunakan persamaan berikut (DJPT, 2015) :

$$
L=L t+(3 \times n \times l \times b)
$$
Persamaan (3)

\section{Keterangan :}

$\mathrm{L} \quad$ : Luas kolam pelabuhan $\left(\mathrm{m}^{2}\right)$

Lt : Luas kolam untuk memutar kapal $\left(\mathrm{m}^{2}\right)$

\& : Jumlah maksimum kapal yang dapat berlabuh (buah)

1 : Panjang kapal rata-rata (meter)

b: Lebar kapal terbesar (meter)

Lt merupakan luas kolam pelabuhan yang dapat digunakan kapal untuk melakukan putaran. Luas kolam ini dapat dihitung dengan menggunakan rumus luas lingkaran sebagai berikut :

$$
L t=\pi r^{2}
$$

Keterangan :

Lt : Luas kolam untuk memutar kapal $\left(\mathrm{m}^{2}\right)$

$\pi \quad: 3,14$

r $\quad$ : Panjang kapal terbesar (meter)

Perhitungan Kedalaman Kolam

Dimana : $\quad D=d+\frac{1}{2} H+S+C$

D : Kedalaman perairan (cm) d : Draft kapal terbesar $(\mathrm{cm})$

$\mathrm{H}$ : Tinggi gelombang maksimum $(\mathrm{Hmaks}=50 \mathrm{~cm})$

S : Tinggi Ayunan kapal yang melaju $(10-30 \mathrm{~cm})$

C : Jarak aman dari lunas kapal ke dasar perairan $(25-100 \mathrm{~cm})$ 
Penetapan lebar bersih di luar kemiringan dasar dan tanggul adalah sebagai berikut (DJPT, 2015) :

- Untuk ukuran kapal sampai 50 GT, lebar bersih 8-10 kali lebar kapal terbesar.

- Untuk kapal ukuran 50-200 GT, lebar bersih 6-8 kali lebar kapal terbesar.

- Untuk kapal-kapal yang lebih besar dari 200 GT, lebar bersih > 6 kali lebar kapal terbesar.

- Analisis rasio penggunaan dermaga

$$
-\mathrm{BOR}=\frac{\Sigma \mathrm{Kapal} \times \mathrm{LB} \times \text { Waktu tambat }}{\text { panjang dermaga } \times \text { waktu tersedia }} \times 100 \%
$$

Keterangan :

LB $\quad: 1,15$ x Panjang Kapal

(m)

Waktu : 3 Hari untuk PPS, 1 Hari

bertambat untuk PPN, PPP,PPI

Waktu : 365 Hari

tersedia

- Penanataan dermaga.

rata-rata kunjungan kapal per hari menurut Sinaga dan Jeluddin, 2014 dengan cara :

$$
R=\frac{\sum k}{\sum h}
$$

Keterangan :

R :Rerata kapal bongkar per hari (unit)

k :Jumlah kapal bongkar per tahun (unit)

h : Hari (365 hari) 


\section{HASIL DAN PEMBAHASAN}

- $\quad$ Analisis Ukuran Dermaga

PPS Nizam Zachman Jakarta memiliki panjang dermaga 2.852 m,yang dikelompokkan berdasarkan letak geografis dermaganya yaitu untuk wilayah timur disebut dermaga timur dengan panjang $775 \mathrm{~m}$, untuk dermaga barat.

Berdasarkan pengukuran yang telah dilakukan terhadap karakteristik kapal perikanan maka didapati rerata panjang kapal keselurahan (LoA) tiap ukuran kapal dengan ukuran 27,67 m, rerata lebar kapal $6.75 \mathrm{~m}$ dan rerata dalam 2,24 $\mathrm{m}$. dengan panjang (LoA) kapal terkecil 16,8 m, lebar 4,4 m dan dalam 1,4 m, sedangkan untuk ukuran kapal terbesar panjang (LoA) kapal terkecil 45,28 m, lebar 9,6 m dan dalam 4,1 m.

\begin{tabular}{|c|c|c|c|}
\hline $\begin{array}{c}\text { Range Ukuran } \\
\text { GT }\end{array}$ & $\begin{array}{c}\text { Rerata Loa } \\
(\mathrm{m})\end{array}$ & $\begin{array}{c}\text { Rerata } \\
\text { Lebar }(\mathrm{m})\end{array}$ & $\begin{array}{c}\text { Rerata Dalam } \\
(\mathrm{m})\end{array}$ \\
\hline $21-30$ & 19.80 & 5.31 & 1.78 \\
\hline $31-50$ & 21.39 & 5.62 & 1.83 \\
\hline $51-100$ & 25.54 & 6.29 & 1.99 \\
\hline $101-200$ & 32.61 & 7.73 & 2.66 \\
\hline $\mathrm{x}>200$ & 38.79 & 8.63 & 3.33 \\
\hline rerata & 27.67 & 6.75 & 2.24 \\
\hline
\end{tabular}

Kemampuan jumlah kapal yang dapat merapat di dermaga dipengaruhi dengan cara kapal tambat di dermaga yaitu dengan cara tambat kapal sejajar (horisontal) dengan dermaga dan kapal tegak lurus (vertikal) dengan dermaga, maka perhitungan kebutuhan dermaganya berbeda, untuk tambat kapal sejajar (horisontal) dengan dengan dermaga menggunakan persamaan (1) dalam metodelogi dimana perhitungan menggunakan panjang kapal keseluruhan (LoA) sedangkan untuk kapal tambat tegak lurus (vertikal) dengan dermaga maka menggunakan persamaan (2) dimana perhitungan menggunakan lebar kapal. 
Jumlah kapal perikanan yang dapat merapat di dermaga apabila cara tambat dengan horisontal sebanyak 88 unit/baris tambat dan jumlah kapal yang dapat merapat tambat dengan vertikal di dermaga sebanyak 251 unit kapal. Cara tambat kapal secara vertikal memberikan keuntungan yaitu dapat menampung lebih banyak kapal. Tetapi, cara tambat secara vertikal memiliki kelemahan dimana pada posisi ini akan menyulitkan kapal untuk melakukan aktivitas, seperti dalam melakukan pendaratan dan perbekalan. Sedangkan cara tambat secara horisontal dapat menampung kapal lebih sedikit dari pada cara tambat vertikal. Tetapi, cara tambat horisontal memberikan keamanan dan kenyamanan kapal dalam menjalankan kegiatan di dermaga, terutama untuk kapal yang melakukan kegiatan pendaratan dan perbekalan.

Umumnya kegiatan pendaratan dan perbekalan kapal menggunakan cara tambat secara horisontal, ini dilakukan untuk kemudahan dalam proses pembongkaran dan kapal lebih stabil di dermaga karena kapal menempel rapat dengan dermaga sedangkan cara tambat secara vertikal digunakan untuk kapal istirahat dan menunggu proses keberangkatan kembali, untuk itu cara tambat kapal dapat disesuaikan dengan kegiatan kapal di pelabuhan.

\section{- Analisis Kolam Pelabuhan}

Luas kolam pelabuhan yang tersedia saat ini di PPS Nizam Zachman Jakarta seluas $40 \mathrm{Ha}$, berdasarkan perhitungan dengan menggunakan persamaan (3) maka didapat jumlah kapal yang dapat ditampung dalam kolam sebanyak 494 unit kapal. Jumlah kapal yang berada di kolam pelabuhan pada bulan Juli 2018 sebanyak 756 unit kapal ini menunjukkan kolam pelabuhan sudah penuh dengan kapal sehingga menyulitkan bagi kapal yang akan masuk dan mendaratkan ikan di pelabuhan. Menurut Lubis dan Mardiana (2011) tentang peranan fasilitas dalam kelancaran operasional pelabuhan perikanan, ketidakcukupan fasilitas dapat menghambat kelancaran aktivitas pelabuhan.

A. Kedalaman Kolam Pelabuhan

Kedalaman kolam yang ada di PPS Nizam Zachman Jakarta sebesar -2,0 s/d -8,0 m (berdasarkan data bathimetri tahun 2015), bedasarkan perhitungan dengan dimensi 
ukuran draft kapal terbesar yaitu 4,1 m $(410 \mathrm{~cm})$ dengan tinggi gelombang maksimum $50 \mathrm{~cm}$, tinggi ayunan kapal yang melaju $20 \mathrm{~cm}$ dan jarak aman dari lunas kapal ke dasar perairan adalah $50 \mathrm{~cm}$ maka kedalaman yang disyaratkan adalah 505 $\mathrm{cm}$ atau 5,05 m, sehingga disimpulkan bahwa kedalaman kolam pelabuhan belum perlu dilakukan pengerukan.

B. Alur Pelayaran

Alur pelayaran digunakan untuk mengarahkan kapal yang akan masuk ke kolam pelabuhan, perencanaan alur pelayaran dan kolam pelabuhan ditentukan oleh kapal terbesar yang akan masuk ke pelabuhan (Triatmodjo, 2010). PPS Nizam Zachman Jakarta merupakan pelabuhan hasil dari reklamasi, alur pelayaran langsung menuju ke laut, tetapi untuk kapal dapat masuk ke pelabuhan melalui pintu masuk dengan dilengkapi dengan dua lampu navigasi dengan lebar pintu masuk saat ini $208 \mathrm{~m}$, ukuran lebar kapal perikanan terbesar yang berada di pelabuhan yaitu KM. Bahtera Indah 28 GT. 395 (terlampir) dengan ukuran lebar kapal sebesar 9,6 m, hasil perhitungan lebar alur pelayaran adalah $57,6 \mathrm{~m}$.

\section{- Analisis Rasio Penggunaan Dermaga/ Berth Occupancy Rate (BOR)}

Berdasarkan data statistik PPS Nizam Zachman Jakarta tahun 2017 jumlah kapal yang berkunjung dihitung sebagai jumlah kapal yang tambat yaitu sebanyak 3.708 kali, rerata panjang kapal 27,67 m, dan waktu tambat yang ditetapkan 3 hari untuk Pelabuhan Perikanan Samudera, berdasarkan nilai rasio yang hasilkan dari perhitungan di atas, rasio pemanfaatan dermaga sebesar 32,66\% dengan waktu tambat 3 hari, menurut Perdirjen No 41 Tahun 2015, tidak perlu dilakukan penambahan dermaga dikarenakan rasio pemanfaatannya kurang dari $80 \%$.

Kapal perikanan yang melakukan tambat di pelabuhan saat ini lebih dari 3 hari. Menurut Mulyana (2016), salah satu penyebab penumpukan kapal di pelabuhan antara lain kebijakan yang tertuang pada Permen KP Nomor 58 tahun 2014 tentang pelaksanaan kebijakan penghentian sementara (moratorium) perizinan usaha perikanan tangkap, alih muatan (transhipment) di laut, dan penggunaan nakhoda dan anak buah kapal (ABK) asing serta moratorium kapal eks asing (Permen KP Nomor 56 Tahun 2014). Selanjutnya menurut Arfan (2017), dalam memenuhi kelengkapan 
persyaratan perijinan, pemilik kapal membutuhkan waktu sedikit lama karena harus diurus di lokasi yang berbeda pada setiap persyaratan. Hasil perhitungan Rasio Penggunaan Dermaga menunjukkan bahwa waktu yang maksimal dapat diterima agar tidak perlu dilakukan penambahan dermaga adalah 6 hari, apabila waktu tambat lebih dari waktu maksimal tersebut maka perlu dilakukan penambahan dermaga.

Berdasarkan hasil penelitian ini, waktu tambat sangat mempengaruhi rasio pemanfaatan dermaga, jika waktu tambat sesuai dengan ketentuan yang berlaku maka tidak sarankan menambah dermaga, untuk itu dapat disimpulkan salah satu penyebab kepadatan kapal di pelabuhan disebabkan oleh waktu tambat yang melebihi ketentuan yang berlaku, semakin lama waktu tambat semakin besar pula nilai rasio pemanfaatan dermaganya.

- Penataan Dermaga Pelabuhan

Pemanfaatan dermaga di PPS Nizam Zachman Jakarta saat ini belum terklasifikasikan dengan baik sesuai peruntukannya. Penataan dermaga dilakukan berdasarkan potensi dan fasilitas yang tersedia di setiap dermaga. Hal ini dilakukan agar pemanfaatan dermaga sesuai dengan aktivitas kapal di dermaga tersebut. Sehingga diharapkan pemanfaatan fasilitas pelabuhan oleh kapal perikanan dapat dilakukan secara optimal.

Berdasarkan bahasan yang telah diuraikan, pembagian zonasi dermaga berdasarkan fasilitas pelabuhan dan aktivitas kapal dapat dilakukan sebagai berikut :

a Kegiatan pendaratan dilakukan Dermaga Barat I, Dermaga Barat II, Dermaga Barat III, Dermaga Selatan.

b Kegiatan perbekalan dilakukan Dermaga Barat IV, Dermaga Jetty I dan Dermaga Jetty II.

c Kegiatan tambat dilakukan di Dermaga Timur

d Kegiatan tambat kapal non perikanan dilakukan di Dermaga Utara. 


\section{Kebutuhan Dermaga Pendaratan}

Dermaga pendaratan merupakan dermaga yang ditujukan untuk mendaratkan ikan hasil tangkapan. Untuk itu dibutuhkan kemudahan dan kenyamanan dalam melakukan kegiatan pembongkaran, maka cara tambat kapal di dermaga pendaratan sejajar (horisontal) dengan dermaga. Kebutuhan dermaga bongkar dihitung dengan menggunakan persamaan (2). Berdasarkan perhitungan kebutuhan dermaga pendaratan dengan rerata kapal yang melakukan aktivitas pendaratan ikan sebanyak 10 unit kapal per hari dan rerata panjang kapal (LoA) sebesar 27,67 m maka kebutuhan ukuran panjang dermaga pendaratan sebesar 307,19 m. Dermaga pendaratan letaknya tidak jauh dari Tempat Pelelangan Ikan (TPI) dikarenakan ikan yang didaratkan harus segera di bongkar dan kapal yang telah melakukan bongkar agar segera keluar dari dermaga pendaratan, dikarenakan dermaga akan digunakan kembali untuk kapal lain yang akan melakukan pembongkaran ikan (Triatmodjo, 2010).

\section{KebutuhanDermaga Perbekalan/perlengkapan}

Dermaga Perbekalan digunakan untuk persiapan perbekalan yang akan dibawa melaut, seperti bahan pokok, air tawar, bahan bakar, es dan sebagainya (Triatmodjo, 2010). Dalam persiapan perbekalan kapal juga membutuhkan kenyamanan, untuk itu kebutuhan dermaga perbekalan dihitung dengan menggunakan persamaan (1). Panjangdermaga perbekalan/perlengkapan sama dengan dermaga pendaratan. maka kebutuhan panjang dermaga perbekalan per hari untuk 10 kapal yang akan berlayar dengan rerata ukuran kapal $27.67 \mathrm{~m}$ sebesar $307.19 \mathrm{~m}$.

\section{Kebutuhan Dermaga Tambat}

Dermaga tambat merupakan dermaga yang digunakan setelah kapal melakukan aktivitas pembongkaran ikan dan $\mathrm{ABK}$ istirahat pulang. Dermaga ini juga dimanfaatkan untuk kapal yang melakukan perawatan kapal (Triatmodjo, 2010). Kebutuhan dermaga tambat ini dihitung berdasarkan cara tambat kapal di dermaga. Kapal di PPS. Nizam Zachman Jakarta tambat secara horisontal dengan dermaga, 
maka kebutuhan dermaga tambat per hari untuk 10 kapal yang berkunjung dengan rerata ukuran kapal $27.67 \mathrm{~m}$ adalah sebesar $307.19 \mathrm{~m}$. Lokasi dermaga tambat diusulkan di Dermaga Timur.

4. Kebutuhan Dermaga Kapal Non Perikanan

Keberadaan kapal non perikanan di PPS Nizam Zachman Jakarta dapat mempengaruhi pemanfaatan dermaga di pelabuhan. Untuk itu kebutuhan dermaga untuk kapal non perikanan ini harus disiapkan juga. Mengingat keberadaan kapal ini merupakan salah satu fasilitas fungsional dalam mendukung aktivitas pelabuhan, serta keberadaannya tidak menghambat aktivitas kapal perikanan.

Hasil dari perhitungan kebutuhan panjang dermaga untuk kapal non perikanan ini sebesar 253,57 m. Lokasi Dermaga Kapal Non Perikanan diusulkan berada di Dermaga Utara, dengan pertimbangan keberadaan kapal non perikanan tidak mengurangi aktivitas kegiatan perikanan dan dikarenakan pada dermaga ini merupakan area tanaman mangrove.

\section{KESIMPULAN}

Pelabuhan Perikanan Samudera Nizam Zachman Jakarta merupakan salah satu pelabuhan perikanan terbesar di Indonesia, dengan klasifikasi type A, pelabuhan ini memiliki panjang dermaga $2.582 \mathrm{~m}$ dan luas kolam $40 \mathrm{Ha}$. Hasil dari penelitian ini dapat disimpulkan sebagai berikut :

1. Panjang dermaga yang tersedia saat ini dapat melayani tambat dengan ukuran kapal rata-rata 27,67 m. Cara tambat dengan horisontal sebanyak 88 unit kapal dan jumlah kapal yang dapat merapat tambat dengan vertikal di dermaga sebanyak 251 unit kapal.

2. Luas kolam pelabuhan yang yang tersedia $40 \mathrm{Ha}$ jumlah kapal maksimum yang berlabuh sebanyak 494 kapal, saat ini jumlah kapal yang berada di kolam pelabuhan sebanyak 756 kapal maka luas kolam pelabuhan saat ini tidak dapat melayani kapal yang tambat namun kedalaman dan alur pelayaran yang tersedia saat ini masih dapat melayani kegiatan kapal di kolam pelabuhan. 
3. Rasio penggunaan dermaga dengan waktu tambat yang ditetapkan yaitu selama 3 hari untuk Pelabuhan Perikanan Samudera. Kapal perikanan yang melakukan tambat di pelabuhan saat ini lebih dari 3 hari hasil perhitungan rasio penggunaan dermaga menunjukkan bahwa waktu yang maksimal dapat diterima agar tidak perlu dilakukan penambahan dermaga adalah 6 hari, apabila waktu tambat lebih dari waktu maksimal tersebut maka perlu dilakukan penambahan dermaga

4. Kondisi saat ini penataan dermaga belum optimal, dikarenakan masih tercampurnya berbagai aktifitas kegiatan di dermaga terdapat aktivitas pendaratan, perbekalan dan tambat. Oleh sebab itu perlu dilakukan penataan dermaga berdasarkan aktivitas kapal.

\section{SARAN}

Saran yang dapat disampaikan dalam tulisan ini adalah sebagai berikut :

1. Zonasi pemanfaatan dermaga oleh kapal perikanan di PPS Nizam Zachman Jakarta sebaiknya dilakukan berdasarkan jenis aktivitas kapal dan ketersedian fasilitas pelabuhan.

2. Mengurangi waktu tambat di pelabuhan dengan cara melakukan percepatan perijinan agar kapal tidak terlalu lama tambat di pelabuhan.

3. Membuat peraturan tentang batas waktu maksimal tambat kapal di pelabuhan.

4. Perlu dilakukan penelitian yang lebih lanjut agar penelitian ini dapat memberikan masukan yang lebih baik, dalam berbagai aspek seperti aspek ekonomi, sosial maupun lingkungan.

\section{DAFTAR PUSTAKA}

Arfan, M. 2017. Implementasi Kebijakan Perizinan Perikanan Tangkap di Kabupaten Pemalang. Jurnal Undip. 1-14

Culin J, Bielic T. 2016. Plastic Pollution From Ships. Pomorski zbornik. (51):57-66

Fyson, J. 1985. Design of Small Fishing Vessels. Fising News LTD. London.England Iskandar, B.H. dan Novita, Y. 1997. Penuntun Praktikum Kapal Perikanan. Jurusan Pemanfaatan Sumberdaya Perikanan. FPIK-IPB. Bogor.

Keputusan Direktur Jenderal Perikanan Tangkap Nomor 41/KEP-DJPT/2015 Tentang Pedoman Umum Perhitungan Penggunaan Fasilitas Di Pelabuhan Perikanan. 
Lubis E. 2006. Buku 1: Pengantar Pelabuhan Perikanan. Bogor: Departemen Pemanfaatan Sumberdaya Perikanan, Fakultas Perikanan dan Ilmu Kelautan, Institut Pertanian Bogor.

Lubis, E. Mardiana N. 2011. Peranan Fasilitas PPI Terhadap Kelancaran Aktivitas Pendaratan Ikan di Cituis Tanggerang, Jurnal Teknologi Kelautan dan Perikanan, 1 (2): 1-10

Mulyana, I. 2016 Pengaruh Pencabutan Subsidi Bbm (Solar) Untuk Kapal >30 GT Terhadap Operasional Penangkapan Kapal Tuna Long Line di PPS Nizam Zachman Jakarta [Skripsi]: Universitas Satya Negara Indonesia, Jakarta

Murdiyanto, Bambang. 2004. Pelabuhan Perikanan. Edisi Pertama. Fakultas Perikanan dan Ilmu Kelautan Institut pertanian Bogor. Bogor. $142 \mathrm{hlm}$.

Nomura, M., dan T. Yamazaki. 1977. Fishing Techniques I. Japan International Coorporation Agency. Tokyo. Japan

Peraturan Menteri Kelautan Dan Perikanan Republik Indonesia Nomor Per. 08/Men/2012 tentang Pelabuhan Perikanan.

Setyawan, A.D dan Winarno, K. 2016. Permasalahan Konservasi Ekosistem Mangrove di Pesisir Kabupaten Rembang, Jawa Tengah. Biodiversitas. 7(2): $159-163$

Sidabur T. 2008. Kondisi Plankton di Teluk Jakarta: Kajian Perubahan Ekologis Teluk Jakarta. Jakarta (ID). LIPI Pr.

Sinaga, Boyma P, Jeluddin Daud. 2014 Kajian Berth Occupation Ratio Di Dermaga Pelabuhan Penyeberangan Sibolga Kaitannya dengan Penyeberangan Sibolga Kaitannya dengan Perkembangan Pelabuhan. Jurnal Departemen Teknik Sipil, Universitas Sumatera Utara.

Triatmodjo, B. 1996. Pelabuhan, Beta offset, Yogyakarta

Triatmodjo, B. 2010. Perencanaan Pelabuhan Cetakan Ke-5. Beta Offset, Yogyakarta.

Undang Undang RI No. 31 Tahun 2004 (diubah dengan UU No. 45 Tahun 2009) Tentang Perikanan.

UPT PPS Nizam Zachman Jakarta, 2017 Profil UPT PPS Nizam Zacahman Jakarta, UPT PPS Nizam Zacahman Jakarta.

UPT PPS Nizam Zachman Jakarta, 2017. Data Statistik Tahun 2017 UPT PPS Nizam Zachman Jakarta. 